\title{
Development of Ceramic Body using Waste Celadon
}

\author{
Jea-Il Lee ${ }^{\dagger}$, Joo-Seok Park*, Yong-Seok Lee, and Byung-Ha Lee \\ Department of Ceramic Engineering, Myongji University, Yongin 449-728, Korea \\ *Korea Institute of Ceramic Engineering and Technology, Seoul 153-801, Korea \\ (Received April 6, 2009; Revised July 13, August 24, 2009; Accepted August 24, 2009)
}

\author{
청자 파도자기를 활용한 도자기 소지 개발 \\ 이제일 · 박주석* · 이용석 · 이병하 \\ 명지대학교 신소재공학과 \\ *한국세라믹기술원 기업협력센터 \\ (2009년 4월 6일 접수 ; 2009년 7월 13일, 8월 24일 수정; 2009년 8월 24일 승인)
}

\begin{abstract}
The yield is increasing as the manufacturing technology of ceramics progresses, however, there are many ceramics of poor quality due to variables upon producing ceramics. Some of those waste ceramics are recycled by sanitary ware or tile manufacturers, but most of them are filled in making environmental problem. Therefore, a research begins to recycle waste ceramic ware as alternative to some imported ceramic ware materials and to reduce environmental pollution. This study, succeeding last study which applied waste white ware as ceramic body material, aimed to solve problems of environment and materials by recycling waste ceradon generated in specially formed areas for ceramic in Gyeonggi-do such as Icheon, Yeoju and Gwangju as the ceramic body material. Consequently, the addition of waste ceramic ware into the ceramic body was judged to have limit up to $30 \%$ according to plasticity measurement. As we added shredded waste ceramic ware as much as $30 \%$ into basic ceramic body and checked its features, the pore rate and absorption rate were good to be average $4 \%$ and $3 \%$ respectively. In addition, it showed strength more than $720 \mathrm{kgf} / \mathrm{cm}^{2}$ which is higher than existing ceradon body on the market with good sinter state; so it is judged to be available or developed as new ceramic body.
\end{abstract}

\section{Key words : Recycle, Waste ceramic, Ceradon, Ceramic body, Environmental problem}

\section{1. 서 론}

우리나라는 오천년의 문화민족으로 토기-청자-분청-백자 로 이어지는 독창적인 도자기 문화를 꽃피워 왔고, 현재에 도 도자기를 통하여 세계적으로 우수한 기술과 아름다움을 알리려는 노력과 연구 활동이 활발하게 이루어지고 있다. ${ }^{1-8)}$

이러한 노력에 의해 도자기 제조 시 공정의 안정성이 이루어져 점점 그 수율은 상당히 향상되어져 왔지만, 아 직 원료, 성형, 소성 등의 각각의 공정에 있어 발생되는 다양한 변수에 대한 복합적이고 정확한 제어가 어렵기 때 문에 다수의 불량품이 발생하고 있는 실정이다. 이외에도 위생도기, 타일, 벽돌업체에서 배출되는 폐기물을 본다면 상당량의 산업폐기물이 발생하고 있다. 이러한 폐기물은 일부 원료로서 재활용되어 타일, 벽돌 산업에 이용되기도 하지만, 양적으로는 미미한 실정으로서, 대부분은 매립에

\footnotetext{
${ }^{\dagger}$ Corresponding author : Jea-Il Lee

E-mail : seasil2@paran.com

Tel : +82-31-241-2067 Fax : +82-31-259-9566
}

의해 처리되고 있고, 이는 심각한 환경문제로서 대두되고 있다. 이러한 세라믹폐기물의 발생에 의한 환경문제를 해 결하기 위하여 일본과 유럽에서는 오래전부터 세라믹업 체와 관련기관의 기술적인 협조와 연구 ${ }^{916)}$ 가 진행되고 있으며, 특히 원료의 재활용에 대한 연구가 활발히 이루 어지고 있으나, 우리나라에서는 아직도 환경오염을 줄이 고 자원을 재활용 하려는 폐기물에 대한 연구는 부족한 상태이다.

이에 본 연구에서는 새로운 도자기소지의 개발 가능성 을 확인하였던 지난 “백자 파도자기를 이용한 도자기 소 지의 개발 연구"17)에 이어 우리나라의 도자기 제조업체 가 밀집되어 있는 경기도 이천 지역에서 발생되는 청자 파도자기를 도자기 소지용 원료로서 재활용하여 청자 및 분청자기의 제조에 적합한 도자기 소지를 개발해 보고자 한다. 이와 같이 청자 파도자기를 사용하여 도자기 소지 를 제조함에 의해 매립에 의해 발생되는 환경 문제를 해 결함과 동시에 자원의 재활용, 특히 일부 수입되어지는 도자기 원료의 대체원료로서의 활용도 기대되어 경제적 효과도 얻을 수 있을 것으로 판단된다. 
Table 1. Chemical Compositions of Raw Materials for Standard Pottery Bodies

\begin{tabular}{|c|c|c|c|c|c|c|c|c|}
\hline Materials & $\mathrm{SiO}_{2}$ & $\mathrm{Al}_{2} \mathrm{O}_{3}$ & $\mathrm{Fe}_{2} \mathrm{O}_{3}$ & $\mathrm{MgO}$ & $\mathrm{CaO}$ & $\mathrm{Na}_{2} \mathrm{O}$ & $\mathrm{K}_{2} \mathrm{O}$ & $\mathrm{TiO}_{2}$ \\
\hline Obu Clay & 49.52 & 31.35 & 2.20 & 1.19 & 2.71 & 0.68 & 0.32 & 0.20 \\
\hline $\begin{array}{c}\text { Hampyeong } \\
\text { Clay }\end{array}$ & 65.71 & 21.25 & 2.67 & 0.83 & 0.34 & 0.84 & 2.43 & 0.89 \\
\hline Seosan Clay & 61.52 & 17.27 & 3.58 & 1.91 & 1.00 & 1.43 & 4.21 & 0.35 \\
\hline $\begin{array}{c}\text { Sanchung } \\
\text { Kaolin }\end{array}$ & 47.31 & 33.02 & 3.57 & 0.37 & 0.23 & 0.10 & 0.79 & 0.30 \\
\hline Icheon Sand & 68.22 & 18.58 & 2.24 & 0.62 & 0.54 & 0.77 & 3.87 & 0.26 \\
\hline $\begin{array}{l}\text { Buyeo } \\
\text { Quartz }\end{array}$ & 99.36 & 0.06 & 0.03 & 0.01 & 0.02 & 0.03 & 0.01 & - \\
\hline $\begin{array}{l}\text { Buyeo } \\
\text { Feldspar }\end{array}$ & 72.70 & 15.90 & 0.26 & - & 0.42 & 5.95 & 3.66 & 0.01 \\
\hline
\end{tabular}

\section{2. 실험방법}

\section{1. 출발 원료}

본 연구에 있어서 기본소지 조합으로서는 시판되고 있 는 청자소지의 광물 분석치를 기초로 하여, 오부점토, 함
평점토, 서산점토, 산청카올린, 이천사토, 부여규석, 부여 장석으로서 청자소지를 조합하였다. 사용되어진 출발원료 에 대한 성분 분석 결과를 Table 1 에, 조합되어진 기본소 지의 조성을 Fig. 1에 각각 나타내었다.

파도자기 원료(W.P.P.: waste pottery and porcelain)는 이 천 지역에서 생산되고 있는 청자 제조업체에서 청자 파 도자기를 수거하여 사용하였다. 이 때 수거된 청자 파도 자기의 성분 분석을 행하였고 그 결과를 Table 2에 나타 내었다. 우선 수거된 청자 파도자기는 flat mill과 ball mill 로서 분쇄하여 $325 \mathrm{mesh}$ 표준체에 전통시켜 미분체로 제 조한 후 기본 소지에 각각 첨가하는 실험에 사용하였다. 분쇄된 파도자기 분말의 입도분포(SALD-7101, Shimadzu, Japan)를 확인한 결과, Fig. 2에 보인 바와 같이 $8 \sim 40 \mu \mathrm{m}$ 의 입도를 나타내었으며 평균입도는 $10 \mu \mathrm{m}$ 를 나타내었다. 또한 분쇄한 파도자기의 결정상을 확인하기 위해 $\mathrm{X}$ 선 회 절분석(XRD-7000, Shimadzu, Japan)을 행하였다. 그 결과 Fig. 3에서와 같이 주결정상은 quartz가 보였으며, 그 외 mullite 결정이 존재하는 것이 관찰되어졌다. 여기에서 관 찰된 결정질 외에 첨가되어 있는 유약 등의 유리질 성분 이 결정생성 및 성장에 영향을 미쳐 강도증진 및 소결밀

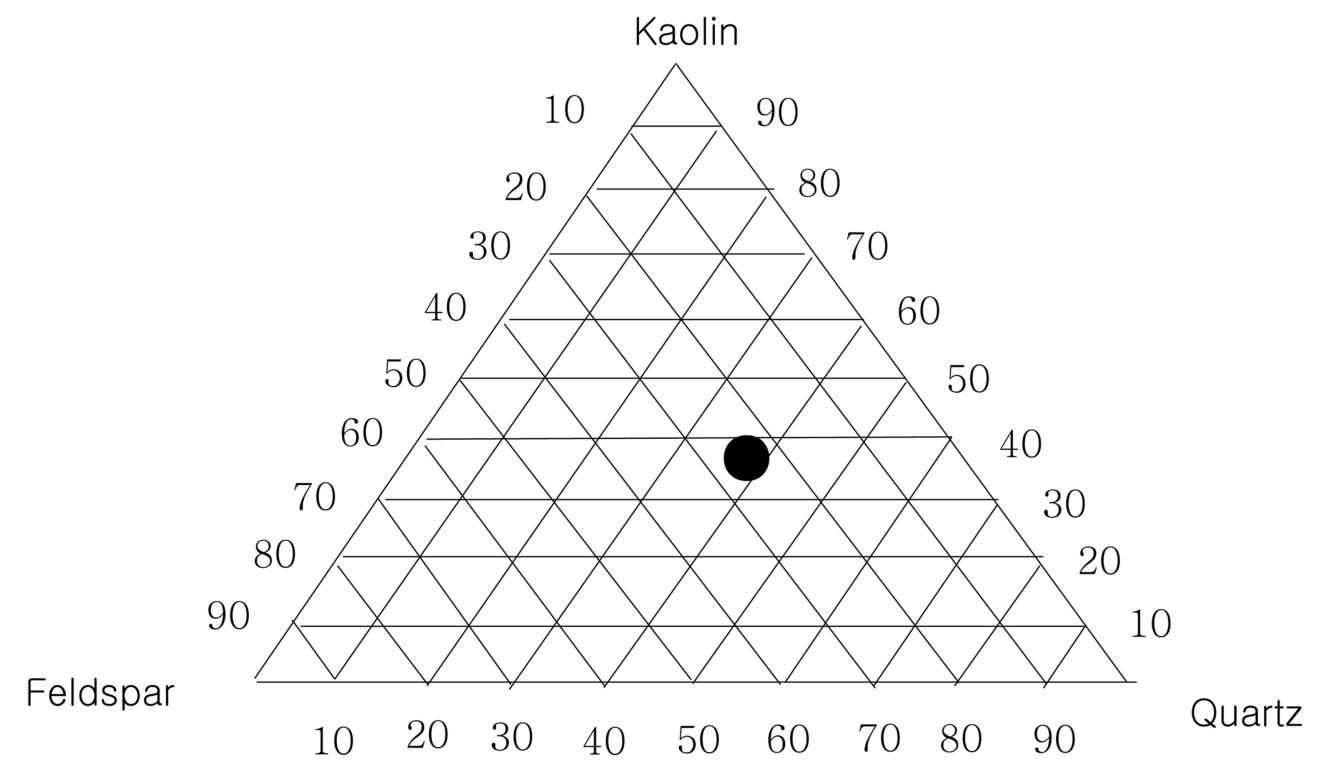

\begin{tabular}{cccccccc}
\hline \multicolumn{10}{c}{ Celadon Body } \\
\hline \multirow{2}{*}{ Materials } & $\begin{array}{c}\text { Obu } \\
\text { Clay }\end{array}$ & $\begin{array}{c}\text { Hampyeong } \\
\text { Clay }\end{array}$ & $\begin{array}{c}\text { Seosan } \\
\text { Clay }\end{array}$ & $\begin{array}{c}\text { Sanchung } \\
\text { Kaolin }\end{array}$ & $\begin{array}{c}\text { Icheon } \\
\text { Sand }\end{array}$ & $\begin{array}{c}\text { Buyeo } \\
\text { Quartz }\end{array}$ & $\begin{array}{c}\text { Buyeo } \\
\text { Feldspar }\end{array}$ \\
\hline \multirow{2}{*}{ wt\% } & 8.0 & 10.0 & 5.8 & 26.0 & 12.8 & 25.3 & 12.1 \\
\hline
\end{tabular}

Fig. 1. Mineral compositions of standard pottery body (wt\%).

Table 2. Chemical Compositions of W.P.P.

\begin{tabular}{cccccccccccc}
\hline & $\mathrm{SiO}_{2}$ & $\mathrm{Al}_{2} \mathrm{O}_{3}$ & $\mathrm{Fe}_{2} \mathrm{O}_{3}$ & $\mathrm{CaO}$ & $\mathrm{MgO}$ & $\mathrm{K}_{2} \mathrm{O}$ & $\mathrm{Na}_{2} \mathrm{O}$ & $\mathrm{MnO}$ & $\mathrm{TiO}_{2}$ & $\mathrm{P}_{2} \mathrm{O}_{5}$ & Ig.loss \\
\hline W.P.P. & 62.01 & 20.96 & 2.95 & 3.60 & 0.66 & 3.13 & 1.11 & 0.05 & 0.29 & 0.13 & - \\
\hline
\end{tabular}




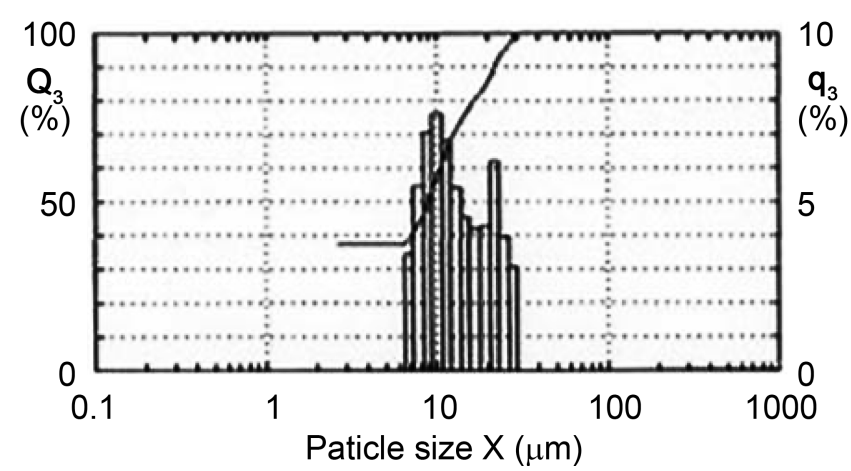

Fig. 2. Particle size distribution analysis of waste pottery and porcelain(W.P.P.) after ball-milling.

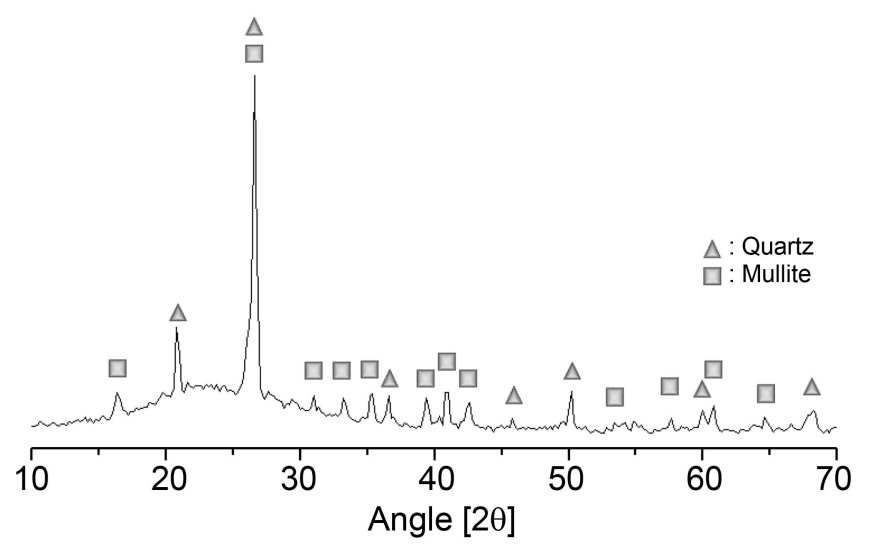

Fig. 3. XRD pattern of waste pottery and porcelain.

Table 3. Compositions of an Experiment

\begin{tabular}{ccc}
\hline & Celadon Body & W.P.P. \\
\hline CW1 & 100 & 0 \\
CW2 & 90 & 10 \\
CW3 & 80 & 20 \\
CW4 & 70 & 30 \\
CW5 & 60 & 40 \\
CW6 & 50 & 50 \\
\hline
\end{tabular}

도 향상 등의 물성 측면에서 좋은 결과를 얻을 수 있을 것으로 판단되어 파도자기도 도자기용 출발원료로서 사 용가능성이 있다고 판단된다.

\section{2. 실험 방법}

\subsection{1. 소지 조합}

파도자기를 활용한 새로운 소지를 개발하기 위하여 Fig. 1 에서 조합된 기본 소지에 파도자기 분쇄분을 Table 3의 조성과 같이 일정량 첨가함으로서 본 실험을 행하였다. 각 조성의 소지에 대해서는 혼합 및 혼련을 행하고 소지 무게의 $16 \sim 18 \%$ 의 수분을 가지도록 조정한 후 7 일간 숙 성을 행하였다.

\subsection{2. 시편성형}

각 조성의 소지에 대한 물리, 화학적 특성을 측정하기 위하여 석고형을 사용하여 시험편을 제작하였다. 강도 측 정용으로 $6 \times 45 \times 8 \mathrm{~mm}$ 의 bar type, 흡수율 측정용으로 $\phi 25 \times 4 \mathrm{~mm}$ 의 disc type의 시험편을 하중연화 측정용으로 $30 \times 130 \times 8 \mathrm{~mm}$ bar type의 시험편을 각각 성형하였다.

\subsection{3. 건조 및 소성}

성형한 시험편이 휨이나 갈라짐, 부분건조가 되는 것을 방 지하기 위하여 $4 \mathrm{~h}$ 간격으로 뒤집으며, 6 일 동안 자연 건조 시킨 후 dry oven에서 완전 건조를 행하였다. 소성은 siliconite muffle furnace를 사용하여 상온 $600^{\circ} \mathrm{C}$ 까지는 $2^{\circ} \mathrm{C} / \mathrm{min}, 600^{\circ} \mathrm{C}$ 에서 소성온도인 $1240 ~ 1260^{\circ} \mathrm{C}$ 까지 $5^{\circ} \mathrm{C} / \mathrm{min}$ 로 승온시켰다. 이 후 1 시간 동안 유지시키고 자연 냉각을 행하였다.

\section{3. 특성분석}

\subsection{1. 가소성 실험}

가소성은 제품의 성형성과 밀접한 관계가 있는 특성으 로서 매우 중요하나, 가소성 측정방법은 현재까지 규격화 된 객관적 측정 방법이 확립되어 있지 않기 때문에 일반 도자기제조업체에서 시행하고 있는 방법에 의거 ${ }^{18)}$ 하여 측 정하였다. 측정법으로서 첫 번째로 건조강도의 확인이다. 건조강도와 가소성은 반드시 일치하는 값은 아니나 대부 분의 소지에서 건조강도가 높은 것이 가소성이 좋다고 알 려져 있어 그에 대한 측정을 행함으로서 가소성을 판단하 였다. 또한 두 번째로 건조성형강도의 측정과 더불어 소 지를 일정한 굵기의 긴 bar형으로 만든 후 이를 손가락에 감았을 때 균열이 생기는 정도를 보고 가소성을 판단하는 방법인 coiling법으로서 측정하여 와목점토를 10 이라는 기 준으로 하였을 때의 각 조성의 소지의 값을 평가하였다.

\subsubsection{DSC-TGA 분석}

각 조성의 소지에 대한 소성온도에 따른 분해, 전이, 새 로운 결정상의 생성 등의 열간 변화를 분석하기 위해 DSC-TGA(STA-MS-Skimmer, Netzsch, Deutschland) 분석 을 $1200^{\circ} \mathrm{C}$ 까지 행하였다.

\subsubsection{SEM 측정}

각 조합비에 따라 소성된 시편의 미세조직을 분석하고 자 각 소성온도로 소결된 시험편의 파단면을 $\mathrm{HF} 40 \%$ 의 용액에 50초간 담가 etching을 행한 다음 SEM(SS-550, Shimadzu, Japan)으로 관찰하였다.

\subsection{4. 물성 측정}

도자기 제조용 소지로서 사용되어지기 위해서는 성형 성 뿐만 아니라 소결 후의 특성, 다시 말해, 흡수율, 기공 율, 강도 등의 특성이 충족되어야 한다. 이에 소성된 시 험편의 흡수율, 기공율, 겉보기비중 측정은 KS L3114에 의해, 수축율은 KS L4004 측정법을 기준으로 측정하였다. 하중연화 측정은 소성 시 시험편의 휨 정도를 측정하여 계산하였으며, 강도 측정은 UTM(MKS Type-PP-650-D, 


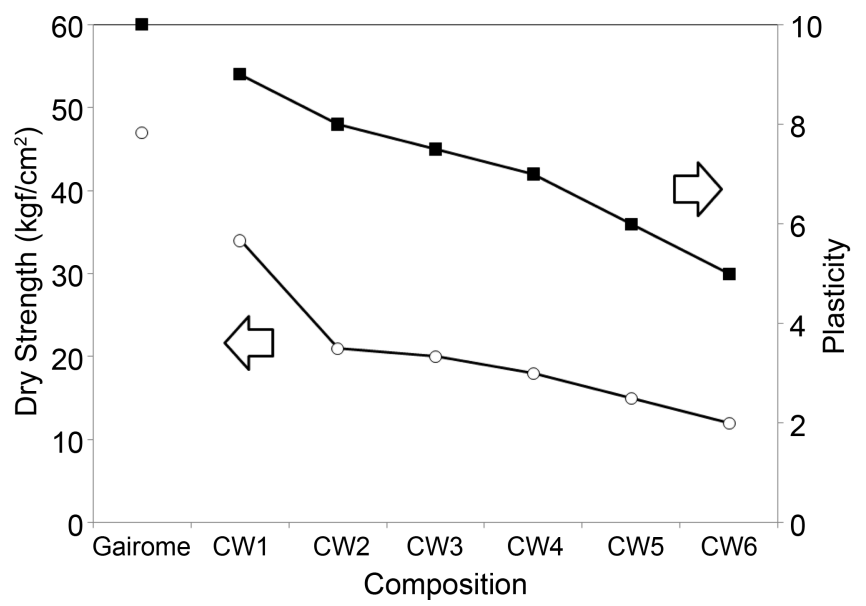

Fig. 4. Result of measurement of plasticity by dry strength and coiling method.

Scientific Instrument, JAPAN)으로서 3점 압축시험법으로 측정하였다.

\section{3. 결과 및 고찰}

\section{1. 가소성 측정}

혼합한 조합에 대한 가소성 측정으로서 건조성형 강도 측정법과 coiling법에 의한 측정을 행하고 그 결과를 Fig. 4에 나타내었다. 대표적인 가소성원료로 알려져 있는 일 본의 와목점토의 가소성 측정값을 기준으로 하여 각 조 성의 가소성을 비교하였다. 건조성형강도의 측정에서는 와목점토 단미의 경우 $47 \mathrm{MPa}$ 의 값을, 기본소지의 경우 에는 $34 \mathrm{MPa}$ 의 값을 나타내었으나 파도자기의 첨가에 의 해 급격하게 건조강도 값이 감소하는 것이 보여졌다. 와 목점토의 측정치를 10 으로 한 후 관찰한 coiling법에 의한 가소성 평가에서도 $\mathrm{CW} 1$ 의 경우 9 정도로서 성형성도 우 수하였으나, 파도자기의 양이 증가됨에 의해 가소성은 현 저히 저하되는 것이 확인되었다.

이러한 파도자기의 첨가량의 증가에 따른 가소성의 감 소는 이미 XRD 분석에서도 보였듯이 파도자기분의 주결 정상은 가소성이 없는 quartz와 mullite로 이루어져 있기 때문이다. 본 실험범위에서는 파도자기 원료가 $30 \%$ 첨가 된 조성까지는 성형이 가능하였으나 그 이상에서는 성형 이 매우 어려웠다. 따라서 가소성 측정으로 본 파도자기 첨가량의 한계는 $30 \%$ 라고 판단되었다.

\subsection{DSC-TGA 분석}

파도자기가 첨가된 각 조성의 소지의 열간 특성 변화 를 확인하기 위한 DSC-TGA 분석을 행하고 그 결과를 Fig. 5에 나타내었다. Fig. 5.(a)의 DSC 측정 결과에서 보 는 바와 같이 각 조성에 있어서 온도변화에 따른 큰 변 화는 보여지지 않았지만, 폐도자기의 첨가량의 증가에 따

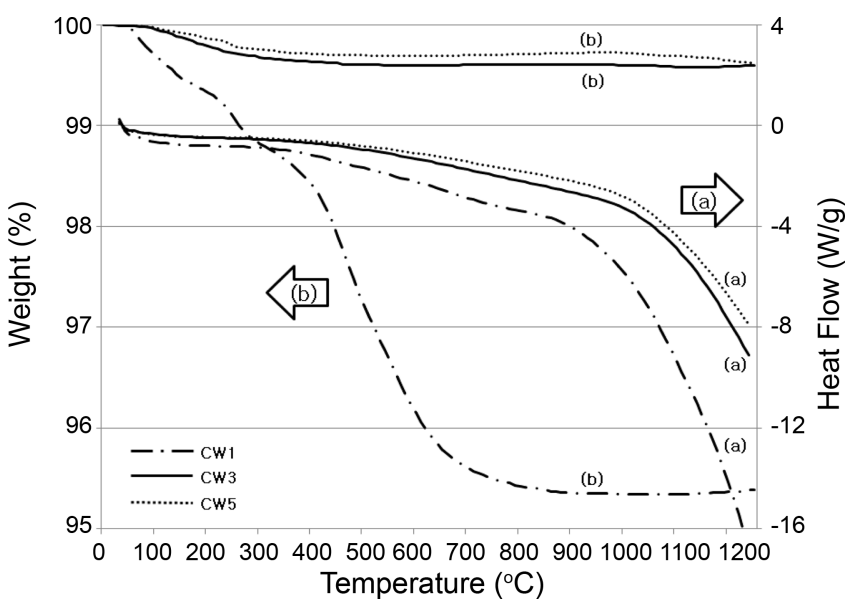

Fig. 5. DSC-TGA curve of each compositions.

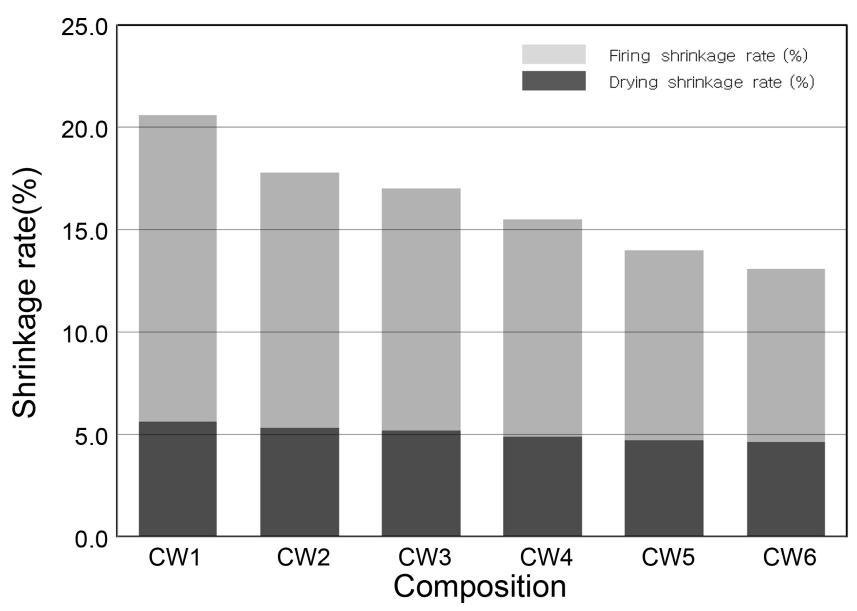

Fig. 6. Drying shrinkage rate and Firing shrinkage rate of each composition (Sintering temperature $; 1250^{\circ} \mathrm{C}$ ).

라 반응개시온도가 조금씩 상승하고 있음이 보여지고 있 다. 또한 Fig. $5(\mathrm{~b})$ 의 $\mathrm{TGA}$ 측정 결과에서는 $\mathrm{CW} 1$ 의 경우 $700^{\circ} \mathrm{C}$ 부근까지 점토 등의 흡착수 및 결정수 탈수 등에 의한 중량감소가 관찰되나, $\mathrm{CW} 3$ 과 $\mathrm{CW} 5$ 조성의 경우에 는 $300^{\circ} \mathrm{C}$ 부근까지 중량감소가 보여지나 $\mathrm{CW} 1$ 에 비해 감 소폭도 미미하게 관찰되었다.

\section{3. 물성 측정 분석}

\subsection{1. 수축율}

Table 3 과 같이 기본 소지에 파도자기 분쇄분을 첨가하 여 조합한 조성에 대해 건조수축율과 소성수축율을 측정 하고 그 결과를 Fig. 6에 나타내었다. 그 결과에서 알 수 있듯이 건조수축율은 모든 조성에서 파도자기 분쇄분의 첨가량이 증가함에 따라 감소하는 것을 확인할 수 있었 다. 또 각 조성의 소지를 $1250^{\circ} \mathrm{C}$ 의 온도영역으로 각각 소 성을 행한 후 측정한 소성수축율 결과에 있어서도 건조 수축율에서의 결과와 같은 경향으로서 기본 소지의 소성 수축율은 $15 \%$ 로 매우 크게 나타났으나, 이후 파도자기의 


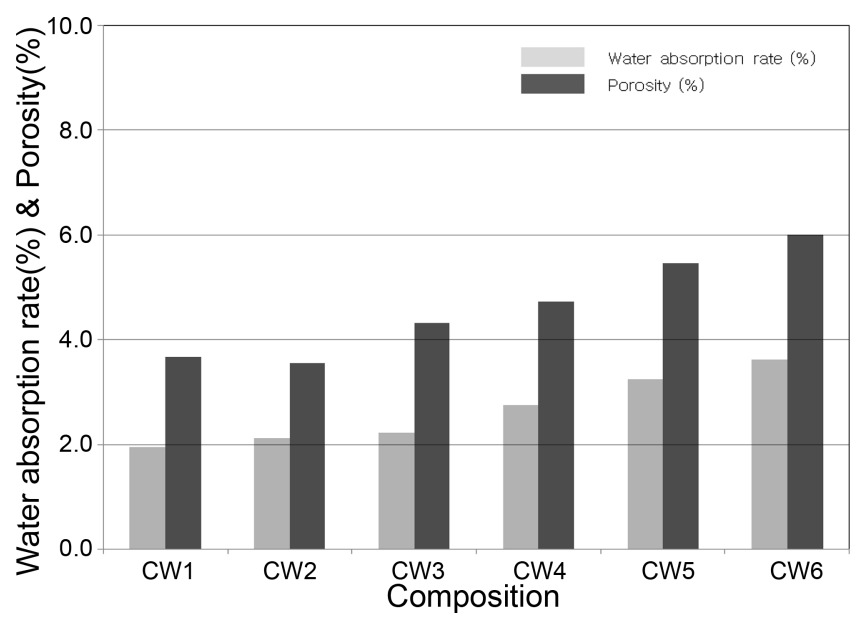

Fig. 7. Porosity and Water absorptivity of each composition sintered at $1250^{\circ} \mathrm{C}$.

첨가량의 증가에 따라 소성수축율도 점점 감소하여 파도 자기를 $30 \%$ 첨가한 조성의 경우 약 $11 \%$ 로 낮아지는 것 이 확인되었다. 이는 파도자기 분쇄분이 수축에 대한 반 응이 없는 chamotte로 작용하여 소지 내의 수축율을 크게 낮추는 역할을 하는 것으로 보인다.

\subsection{2. 흡수율 및 기공율}

각 조성의 소지를 $1250^{\circ} \mathrm{C}$ 로 소성한 후 시험편의 기공율 과 흡수율을 측정하고, 그 결과를 Fig. 7에 나타내었다. 기 본 소지에 파도자기 분쇄분이 첨가됨에 따라 흡수율과 기 공율은 분쇄분의 첨가량이 증가함에 따라 그 값은 증가 하는 경향이 나타났다. 기공율의 경우, $\mathrm{CW} 1$ 이 $3.6 \%$ 정도 임에 반해 파도자기 $50 \%$ 첨가된 $\mathrm{CW6}$ 는 $6 \%$ 정도였고, 흡수율의 경우에도 $\mathrm{CW} 1$ 은 $2 \%$ 정도였지만 $\mathrm{CW} 6$ 조성은 $3.6 \%$ 정도로서 나타났다.

이러한 기공율 및 흡수율의 증가에 대한 이유를 확인 해 보고자 기본 소지와 파도자기를 $30 \%$ 첨가한 소지를 $1250^{\circ} \mathrm{C}$ 로 소성한 시험편의 미세구조를 관찰하고 그 결과 를 Fig. 8 에 나타내었다. 기본소지인 $\mathrm{CW} 1$ 의 경우 치밀한 미세구조를 나타내고 있으나, 이에 비해 파도자기가 $30 \%$ 첨가된 $\mathrm{CW} 4$ 조성의 경우에는 기본소지에 비해 기공이

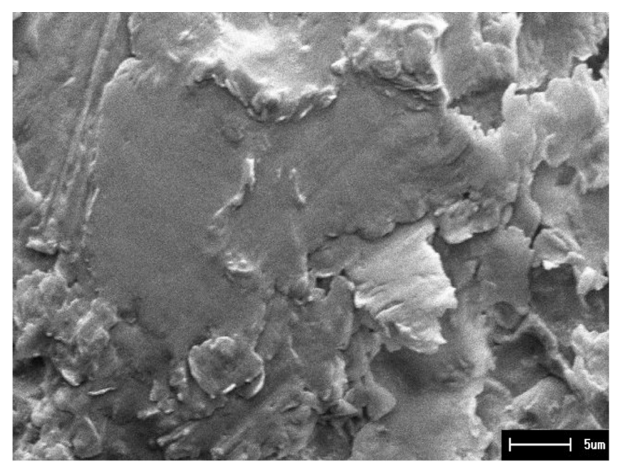

(a) CW1

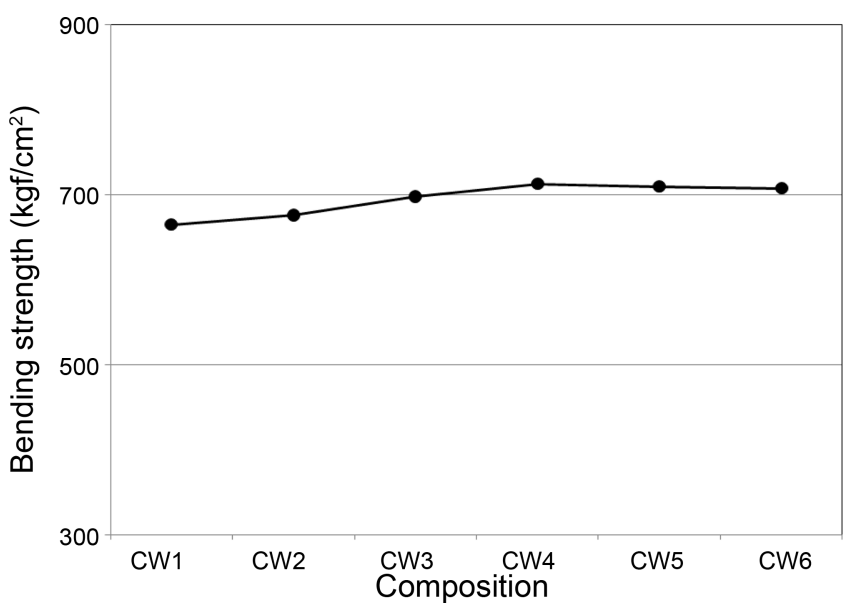

Fig. 9. Bending strength of each composition sintered at $1250^{\circ} \mathrm{C}$.

많은 미세구조가 관찰되어 이에 소결이 충분히 이루어지 지 않았음이 보여졌다. 이는 파도자기분이 chamotte로서 작용하여 그 함량 증가에 따라 소결성을 방해하여 그로 인해 흡수율과 기공율이 증가하게 되었다고 보인다.

3.3.3. 굽힘강도 및 하중연화

조합된 각 조성에 대한 굽힘강도 측정은 $1250^{\circ} \mathrm{C}$ 소성 시편에 대해 행하고 그 결과를 Fig. 9에 나타내었다. 기 본소지인 $\mathrm{CW} 1$ 조성의 굽힘 강도값은 $665 \mathrm{kgf} / \mathrm{cm}^{2}$ 로 측정 되었는데 파도자기 분쇄분의 첨가량의 증가에 따라 $30 \%$ 까지는 증가하여 $713 \mathrm{kgf} / \mathrm{cm}^{2}$ 을 나타내고 있음이 확인되 었다. 하지만 그 이상의 첨가량에서는 큰 강도변화를 보 이지 않고 미미하지만 조금 감소하는 경향을 보였다. 이 는 앞서 흡수율 등의 물성 평가 결과와 같이 파도자기 함 량 증가에 따른 소결성의 저하에 따른 것으로 보여진다.

Fig. 10에 나타낸 하중연화 측정 결과에서는 파도자기의 첨가량이 증가함에 따라 변형이 낮아지는 것이 확인되어 졌다. $1250^{\circ} \mathrm{C}$ 소성의 경우 $\mathrm{CW} 1$ 에서 $12 \mathrm{~mm}$ 정도이던 변 형률이 $\mathrm{CW} 4$ 에서는 $6 \mathrm{~mm}$ 까지 낮아졌고, $\mathrm{CW} 6$ 조성에서는 $2 \mathrm{~mm}$ 까지 떨어져 거의 변형이 일어나지 않았음이 확인되 었다. 이러한 낮은 하중연화 측정치를 나타낸 파도자기 첨

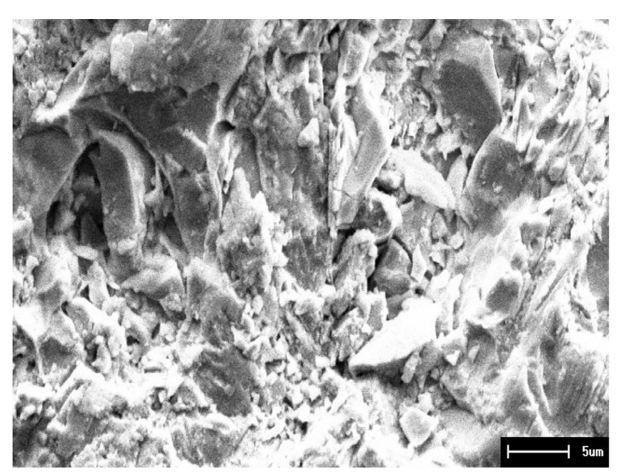

(b) CW4

Fig. 8. SEM photographs of each composition sintered at $1250^{\circ} \mathrm{C}$. 


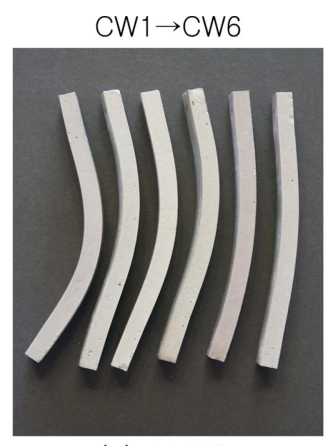

(a) $12400^{\circ} \mathrm{C}$
$\mathrm{CW} 1 \rightarrow \mathrm{CW} 6$

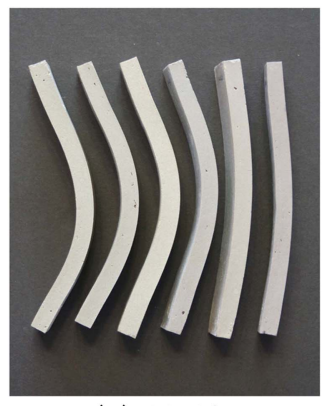

(b) $1250^{\circ} \mathrm{C}$
$\mathrm{CW} 1 \rightarrow \mathrm{CW} 6$

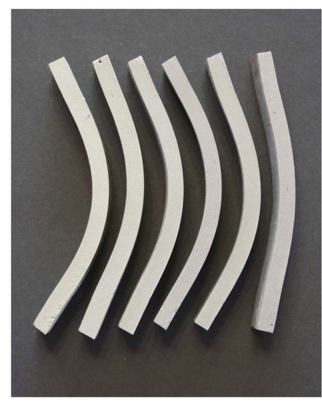

(c) $1260^{\circ} \mathrm{C}$

\begin{tabular}{cccc}
\hline \multirow{2}{*}{ Composition } & \multicolumn{3}{c}{ Results of load testing $(\mathrm{mm})$} \\
\cline { 2 - 4 } & $1240^{\circ} \mathrm{C}$ & $1250^{\circ} \mathrm{C}$ & $1260^{\circ} \mathrm{C}$ \\
\hline CW1 & 11 & 12 & 14 \\
CW2 & 8 & 10 & 11 \\
CW3 & 7 & 8 & 9 \\
CW4 & 4 & 6 & 7 \\
CW5 & 2 & 3 & 6 \\
CW6 & 1 & 2 & 4 \\
\hline
\end{tabular}

Fig. 10. Result of load testing of each composition at various temperature.

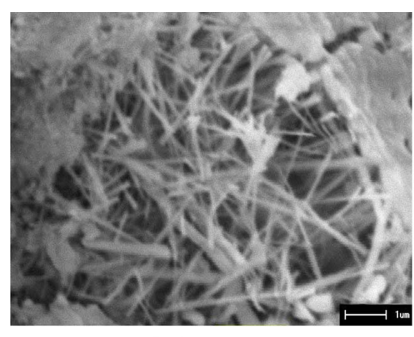

(a) $\mathrm{CW}_{1}$

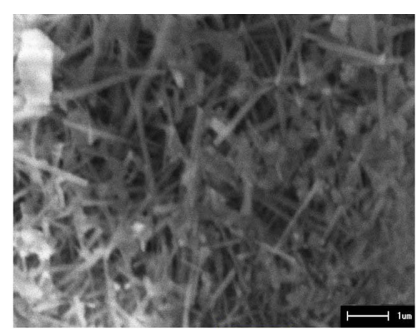

(b) CW2

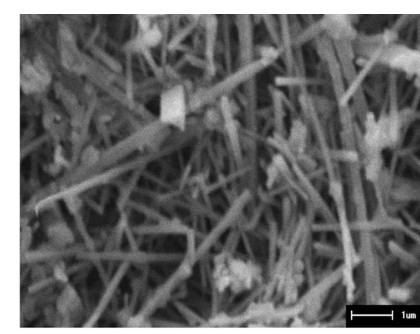

(c) CW4

Fig. 11. SEM photographs of each composition body sintered at $1250^{\circ} \mathrm{C}$.

가 소지를 이용하면 기물의 변형을 적게 할 수 있으므로 큰 도자기 기물의 제조에 적용 가능하다고 생각된다.

\subsubsection{SEM 분석}

각 조성별 소지의 미세구조 및 mullite 결정 상태을 확인 해 보고자 SEM 분석을 행하고 그 결과를 Fig. 11에 나타 내었다. 각 조성의 시편은 먼저 $\mathrm{HF} 40 \%$ 의 용액에 50 초간 담그는 조건으로 에칭을 행하였다. 그 결과, 기본소지에 파 도자기분을 $10 \%$ 씩 증가시킴에 따라 $\mathrm{CW} 4$ 조성까지는 mullite 결정이 조금씩 성장되고 있음이 확인되었다. 이러 한 mullite 생성과 성장에 의한 미세구조의 변화가 굽힘 강도값의 증가에 기인하였다고 판단되었다. 이 이상의 조 성인 $\mathrm{CW} 5, \mathrm{CW} 6$ 조성에서는 $\mathrm{CW} 4$ 와 미세구조상에 큰 차 이는 보여지지 않았다.

\section{4. 결 론}

청자 파도자기 분쇄분을 사용하여 새로운 재활용 도자
기 소지의 개발에 대한 실험 결과, 다음과 같은 결과를 얻었다.

(1) 본 실험범위에 있어, 파도자기가 첨가된 전 조성에 걸 쳐서 기존 청자소지의 소성온도와 같은 온도영역인 $1250^{\circ} \mathrm{C}$ 영역에서 소성이 가능하였다. 이는 청자 파도자기 분쇄분 중에 포함되어 있는 유약의 일부 알카리 성분이 소성시 바인더 역할을 하였기 때문이라 판단되어진다.

(2) 본 실험범위에 있어, 청자소지로서의 활용을 위한 가소성 측정에서는 파도자기의 첨가 한계는 $30 \%$ 였다. 이 청자 파도자기가 $30 \%$ 첨가된 $\mathrm{CW} 4$ 소지의 경우 $1250{ }^{\circ} \mathrm{C}$ 로 소결한 경우, 기공율은 평균 $4 \%$, 흡수율은 평균 $3 \%$ 로 양호한 값을 나타내었으며, 굽힘강도 값도 $720 \mathrm{kgf} / \mathrm{cm}^{2}$ 로서 기존 시판중인 청자소지보다 높은 값을 보였다.

(3) 재활용 도자기용 원료로서 청자 파도자기 분쇄분을 사용함에 의해 환경오염 문제를 해결할 수 있으며, 제조 원가의 절감 뿐만 아니라 chamotte 대용으로 사용함으로 서 변형과 파손율이 적은 우수한 특성을 가지는 새로운 
도자기 소지로서의 활용이 기대되어진다.

\section{REFERENCES}

1. J. H. Lee, E. S. Na, and S.C.Choi, "A Study on the Effect of Residual Stress between Body and Glaze of Pottery on the Mechanical Strength," Kor. J. Mat. Res., 9 [2] 181-86 (1999).

2. Y. G. Jung, "Effect of Firing Temperature on Mechanical Property and Contact Damage in Pottery," J. Kor. Ceram, Soc., 35 [12] 1343-50 (1998).

3. W. M. Carty and U. dnSenapati, "Porcelain-Raw Materials, Processing, Phase Evolution and Mechanical Behavior," $J$. Am. Ceram. Soc., 81 [1] 3-20 (1998).

4. A. W. Norris, D. Taylor, and I. Thorpe, "Range Curve: An Experimental Method for the Study of Vitreous Pottery Bodies," Trans. J. Br. Ceram. Soc., 78 102-8 (1992).

5. Y. Kobayashi, O. Ohira, Y. Ohashi, and E. Kato, "Effect of Firing Temperature on Bending Strength of Porcelain for Tableware," J. Am. Ceram. Soc., 75 [7] 1801-6 (1992).

6. H. J. Lim, S. C. Choi, E. S. Lee, and J. S. Lee, "Effect of Processing Parameters on the Densification - Behaviors by Low Shrinkage in Clay Materials," J. Kor. Ceram. Soc., 33 [7] 725-34 (1996).

7. E. S. Lee, "Studies on the Mechanical Properties of Porcelain Bodies," J. Kor. Ceram. Soc., 11 [3] 69-79 (1974).

8. R. C. Bradt, "A High-Tech Approach to a Traditional Ceramic-The Toughness of Porcelain," pp. 15 22 in proceeding of International Symposium on Fine Ceramics Arita 86, 1986.

9. F. Andreola, L. Barbieri, A. Corradi, I. Lancellotti, and T. Manfredini, "Utilisation of Municipal Incinerator Grate Slag for Manufacturing Porcelainized Stoneware Tiles Manufacturing," J. Eur. Ceram. Soc., 22 [9-10] 1457-62 (2002).

10. I. Agote, A. Odriozola, N. Gutierrez, A. Santamaria, J. Quintanilla, P. Coupelle, and J. Soares, "Rheological Study of Waste Porcelain Feedstocks for Injection-Molding," $J$.
Eur. Ceram. Soc., 21 [16] 2843-53 (2001).

11. A. P. Luz, S. Ribeiro, "Use of Glass Waste as a Raw Material in Porcelain Stoneware Tile Mixtures," Ceramics International, 33 761-65 (2007).

12. R. R. Menezes, H. G. Malzac Neto, L. N. L. Santana, H. L. Lira, H. S. Ferreira, and G A. Neves, "Optimization of Wastes Content in Ceramic Tiles Using Statistical Design of Mixture Experiments," J. Eur. Ceram. Soc., 28 3027-39 (2008).

13. R. R. Menezes, H. S.Ferreira, G. A. Neves, H. de L. Lira, and H. C. Ferreira. "Use of Granite Sawing Wastes in the Production of Ceramic Bricks and Tiles," J. Eur. Ceram. Soc., 25 [7] 1149-58 (2005).

14. F. A. Costa Oliveira, V. Livramento, F. Delmas, "Novel Mullite-based Ceramics Manufactured from Inorganic Wastes I. Densification Behaviour," J. Mater. Pro. Tech., 196 101-8 (2008).

15. J. O. Hong, S. G. Kang, K. G. Lee, Y. T. Kim, Y. J. Kim, J. H. Kim, and M. S. Park, "Characteristics of Sintered Bodies Made from the System of Paper Sludge Ash-Fly Ash-Clay," J. Kor. Ceram. Soc., 38 [10] 908-13 (2001).

16. S. W. Lee, H. J. Kim, and E. H. Kim, "Control of Permanent Shrinking of Recycled Castable Refractories from Waste Refractories of $\mathrm{Al}_{2} \mathrm{O}_{3}-\mathrm{SiO}$," J. Kor. Ceram. Soc., 29 [1] 1522 (1992).

17. J. I. Lee, Y. S. Lee, and B. H. Lee "Ceramics Body Development Using Waste Whiteware," J. Kor. Ceram. Soc., 43 [10] 626-34 (2006).

18. B. S. Han, "Test and Characterization of Porcelain Body," 14th Pottery Symposium in Korea, 14 47-58 (2001).

19. H. Schneider, K. Okada, and J. A. Pask, "Mullite and Mullite Ceramics," John Wiley \& Sons, 148-67 (1994).

20. I. S. Kim, S. W. Kang, J. S. Park, M. W. Lee, B. H. Lee, and K. H. Lee, "Influence of Mullite-seed on the Mullite Synthesis from Various Compositions," J. Kor. Ass. Crystal Growth, 10 [1] 48-54 (2000). 